OPEN ACCESS

Edited by:

Gislane Lelis Vilela de Oliveira São Paulo State University, Brazil

Reviewed by:

Tu Mai,

University of Texas Health Science Center at Houston, United States Bernahrd Ryffel,

Centre National de la Recherche Scientifique (CNRS), France

*Correspondence:

Fariba Ghiamati Yazdi f.ghiamatiyazdi@uu.nt

Sabihe Soleimanian-Zad soleiman@iut.ac.ir

Specialty section

This article was submitted to Mucosal Immunity, a section of the journal Frontiers in Immunology

Received: 11 April 2020 Accepted: 06 May 2020

Published: 04 June 2020

Citation: Ghiamati Yazdi F, Zakeri A, Ark IV, Leusink-Muis T, Braber S, Soleimanian-Zad $S$ and Folkerts $G$ (2020) Crude Turmeric Extract Improves the Suppressive Effects of Lactobacillus rhamnosus GG on

Allergic Inflammation in a Murine Model of House Dust Mite-Induced Asthma. Front. Immunol. 11:1092. doi: 10.3389/fimmu.2020.01092

\section{Crude Turmeric Extract Improves the Suppressive Effects of Lactobacillus rhamnosus GG on Allergic Inflammation in a Murine Model of House Dust Mite-Induced Asthma}

\author{
Fariba Ghiamati Yazdi ${ }^{1,2 *}$, Amin Zakeri ${ }^{3}$, Ingrid van Ark ${ }^{2}$, Thea Leusink-Muis ${ }^{2}$, \\ Saskia Braber ${ }^{2}$, Sabihe Soleimanian-Zad ${ }^{1 *}$ and Gert Folkerts ${ }^{2}$

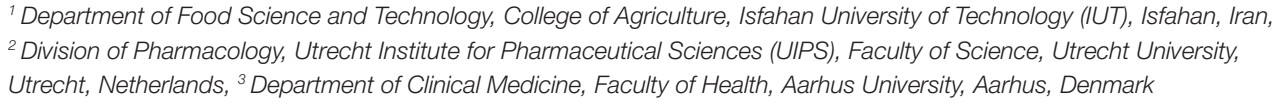

There is a strong correlation between dysregulation of the gastrointestinal microbiota and development of allergic diseases. The most prevalent therapies for relieving asthma symptoms are associated with serious side effects, and therefore novel approaches are needed. Our objective was to elucidate whether oral administration of Lactobacillus rhamnosus GG (LGG) as a probiotic or turmeric powder (TP) as a prebiotic or both as a synbiotic mitigate allergic inflammation including lung function, airway inflammatory cell infiltration, Th2 cytokines/chemokine in a murine model of house dust mite (HDM)induced asthma. BALB/c mice were intranasally sensitized and challenged with HDM received TP (20 mg/Kg mouse), or/and LGG (10 ${ }^{5}$ or $\left.10^{7} \mathrm{cfu} / \mathrm{ml}\right)$, or both orally. Interestingly, the synbiotic intervention (HDM-TP-LGG E7) specifically suppress the developement of airway hyperresponsiveness in response to methacholine. Besides, our synbiotic, TP, and LGG strongly down-regulated eosinophilia, IL-5, CCL17, IL-13. In terms of $\mathrm{T}$ cell response, CD4 ${ }^{+}$Th2 cells and CD4 ${ }^{+}$Th17 population were reduced in the splenocytes of the treatment groups compared to control. The synbiotic group not only elevated $\mathrm{CD} 25^{+}$Foxp3 ${ }^{+}$Treg frequency compared to asthmatic group, but also increased $T$ reg cells compared to the probiotic group. The synbiotic also indicated the superior effect in suppressing Th2 cells compared to probiotic. Although, TP and LGG alone displayed suppressive effects, this study showed that the combination therapy consisting of TP and LGG (synbiotic) is more effective in some of the parameters than either of the treatments alone. This novel synbiotic, might be considered as a potential food-based drug for translational medicine and can possibly be used along with corticosteroid treatment.

Keywords: HDM-induced asthma, synbiotic, probiotic, Lactobacillus rhamnosus GG, allergic diseases, turmeric 


\section{INTRODUCTION}

Asthma is a complicated chronic disease of which the underlying immunological processes are still not well-grounded. According to the World Health Organization report, asthma is the most common non-communicable disease among children. It is estimated that about 235 million people currently suffer from asthma in which the majority of deaths occurs in the elderly. In terms of health economics, asthma has imposed a severe burden on the healthcare systems. There are many factors associated with the increasing frequency and severity of asthma, including genetic predisposition, allergen exposure, air pollution, and lifestyle. Allergic asthma is recognized by a dominant Th2 response causing insufficient lung function, airway inflammation, increased total IgE levels, and eosinophilia in bronchoalveolar lavage fluid (BALF) (1-3).

Currently, the most common therapies to control asthma symptoms are long-acting beta-agonists and corticosteroids. Substantial evidences show that long-term use of corticosteroids can cause corticosteroid-resistance leading to a poorly controlled disease. Besides, many side effects have been reported, including weight loss, growth reduction, increasing blood pressure, muscles, and bones atrophy. Thus, there is an urgent need for novel treatments with long-term persistence, stronger symptom alleviation, and minimum side effects $(1,2,4,5)$.

It is postulated that certain microorganisms and/or their metabolites can shift the inflammatory responses to Thl. On the other hand, they may augment the production of regulatory cytokines by proliferation of regulatory $\mathrm{T}$ cells (Treg). Interestingly, both levers (Th1 and Treg) can lead to downregulation of allergen specific Th2 responses. In this regard, the intestinal microbiota can play a central role in governing hyperactivation of cells toward balanced circumstance $(2,5,6)$.

Probiotics are defined as the non-pathogenic microorganisms that award healthiness to host when are consumed in adequate numbers (6). They are able to affect both local (intestine) and systemic inflammation by secretion of several metabolites, like antimicrobial products or so-called "bacteriocin" and short chain fatty acid (SCFA) (7), selective enteric pathogen exclusion, stimulating intestinal tight junction network, and regulation of immunological responses (8).

Given the anti-inflammatory effect of probiotics, numerous studies have been conducted to evaluate their therapeutic effects on alleviating allergic asthma symptoms (9-14). Sagar et al. reported the promising effect of Lactobacillus rhamnosus and Bifidibacterium animalis bb12 on the reduction of lung resistance in the ovalbumin-induced allergic asthma in mice (1). Similarly, $\mathrm{Wu}$ et al. demonstrated that oral pre- and post-treatment of Lactobacillus rhamnosus GG not only decrease the lung resistance but also reduce BALF inflammatory cell filtration and $\mathrm{Th}_{2}$ cytokines in mice (2).

The growth, activity, and colonization of probiotic in GI can be stimulated by the use of prebiotics. Prebiotics are regarded as non-digestible food constituents consumed by probiotics. The synbiotic concept refers to the combination of pro- and prebiotics $(11,15,16)$.
A growing body of clinical trials, epidemiological studies as well as animal experiments have described herbaceous medicines as novel complementary therapeutic modalities for many diseases $(10,17,18)$.

Turmeric is a complex compound derived from the Curcuma longa rhizomes. According to our pervious study, the chemical analysis of turmeric extract indicated several components including curcumin (polyphenol yellowish pigment of turmeric $2-5 \%)$, carbohydrates $(40-70 \%)$, proteins $(6-8 \%)$, oils $(5-8 \%)$, and other elements $(3-5 \%)(19,20)$. Turmeric has well-known pharmacological activities such as anti-inflammatory function. In addition, it has recently attracted attentions as a potential prebiotic compound $(17,19)$.

Although most animal models of asthma studies have focused on the effect of curcumin or probiotic bacteria alone, the effect of crude turmeric combined with a probiotic bacterium has poorly been addressed $(19,21)$. It was, therefore, the aim of this study to explore the effects of long-term treatment with Lactobacillus rhamnosus GG, turmeric powder, and their combination on airway inflammation. In order to induce an allergic asthma model, mice were sensitized and challenged with house dust mite (HDM) Pro-, pre-, and synbiotic were administrated orally and compared to budesonide as a standard therapy.

The present study indicates that a novel synbiotic can potentially synergize the protective effects of probiotic and prebiotic in context of allergic airway inflammation via suppression of airway hyperresponsiveness (AHR) BALF eosinophilia, and Th2 cells and associated cytokines accompanied by induction of regulatory $\mathrm{T}$ cells.

\section{MATERIALS AND METHODS}

\section{Mice}

Male BALB/c mice at 6-8 weeks of age with body weights of $20-25 \mathrm{~g}$ were purchased from the Charles River Laboratories, France and were acclimatized for 1 week prior to the start of the experiments. Mice were housed in filter-topped makrolon cages (Plexx, The Netherlands) and had free access to food and water. The AIN93G control diet (Research Diet Services, The Netherlands) was used to feed the mice ad-libitum during the entire experimental period. All in vivo experiments were performed in accordance with the Guidelines of the Dutch Committee of Animal Experiments (Utrecht, the Netherlands).

\section{The Probiotic and Prebiotic}

Lactobacillus rhamnosus GG-ATCC 53103 (LGG) was purchased from the American Type Culture Collection (USA). A capsule of LGG was inoculated in MRS broth (Oxoid, UK) at $37^{\circ} \mathrm{C}$ overnight and bacteria were harvested in the late logarithmic phase by centrifugation $(3,200 \mathrm{~g}, 10 \mathrm{~min})$, washed with phosphate buffered saline (PBS, Dulbecco's phosphate-buffered saline, Sigma) twice and counted by spectroscopy method (optical density) and plating serial dilutions $(19,21)$. According to the growth curve obtained from daily monitoring of Lactobacillus rhamnosus GG-ATCC 53103, active fresh bacteria prepared daily in the sterile PBS for oral treatments in two different doses $(5 \times$ $10^{5} \mathrm{cfu} / \mathrm{ml}, 200 \mu \mathrm{l}$ and $\left.5 \times 10^{7} \mathrm{cfu} / \mathrm{ml}, 200 \mu \mathrm{l}\right)$. 
Rhizomes of Curcuma longa plant (turmeric) used in this study were provided from the local markets of Isfahan province, Isfahan, Iran. The rhizomes were peeled, chopped and blended with a miller (HR 2061; Philips, Netherland), and being passed through a sieve (mesh number $140,105 \mu \mathrm{m}$ hole size) to make turmeric powder (TP) for further experiment. TP was dissolved in PBS to achieve an appropriate concentration. The solution was sterilized by autoclave to prevent microbial contamination.

\section{Murine HDM-Induced Asthma Model}

$\mathrm{BALB} / \mathrm{c}$ mice were intranasally sensitized on day 0 with $1 \mu \mathrm{g}$ HDM (Greer Laboratories, Lenoir, USA)/40 $\mu \mathrm{L}$ PBS (Lonza, Walkersville, USA) or PBS alone under the mild anesthetic circumstance induced by isoflurane inhalation. The protocol was followed by intranasal challenges once a day from day 7 to 11 with $10 \mu \mathrm{g} \mathrm{HDM} / 40 \mu \mathrm{L}$ PBS or PBS alone (HDM-PBS = positive control groups or PBS-PBS = negative control groups) (Figure 1 and Table 1) (1, 3, 4, 22). The test groups include: PBS-PBS (control negative group): PBS sensitized, challenged and treated mice, PBS-TP: The control of prebiotic (TP) group was sensitized and challenged with PBS and orally treated once a day with TP (20 mg/kg) (17), PBS-TP- LGG E7: The synbiotic control group was sensitized and challenged with PBS and treated (oral gavage) with a $200 \mu \mathrm{l}$ mixture of TP $(20 \mathrm{mg} / \mathrm{kg})$ and $10^{7} \mathrm{cfu}$ LGG /mouse HDM-PBS (control positive group): HDM sensitized and challenged, and PBS treated mice, HDM-CS: As a treatment positive control, intratracheal instillation from day 7 till 11 with the corticosteroid budesonide (CS) as HDM-CS group $(500 \mu \mathrm{g} / \mathrm{kg}, 40 \mu \mathrm{l})$, the prevalent therapy for asthmatic patients, was performed once a day to determine the effectiveness of our treatments. HDM- LGG E5: The probiotic group 1 was sensitized and challenged with HDM and treated (oral gavage) with $200 \mu \mathrm{l}$ of $10^{5} \mathrm{cfu} /$ mouse LGG, HDM-LGG E7: The probiotic group 2 was sensitized and challenged with HDM and treated (oral gavage) with $200 \mu \mathrm{l}$ of $10^{7} \mathrm{cfu} /$ mouse LGG (Figure 1 and Table 1) (1, 3, 4, 22) HDM-TP: The prebiotic (TP) group was sensitized and challenged with HDM and orally treated once a day with TP (20 mg/kg), HDM-TP-LGG E5: The synbiotic group 1 was sensitized and challenged with HDM and treated (oral gavage) with a $200 \mu \mathrm{l}$ mixture of TP $(20 \mathrm{mg} / \mathrm{kg})$ and $10^{5} \mathrm{cfu}$ LGG /mouse, HDM-TP-LGG E7: The synbiotic group 2 was sensitized and challenged with HDM and treated (oral gavage) with a 200 $\mu l$ mixture of TP $(20 \mathrm{mg} / \mathrm{kg})$ and $10^{7} \mathrm{cfu}$ LGG /mouse. The oral treatments started 2 weeks before sensitization (day 0 ) and were continued throughout the entire procedure (day 11). Mice were sacrificed on day 14 by pentobarbital overdose (Figure 1 and Table 1) (1, 3, 4, 22).

\section{Airway Responsiveness Measurement}

On day 14, mice underwent anesthesia by intraperitoneal injection of a K-M-mixture containing ketamine (Vetoquinol S.A., France; $125 \mathrm{mg} / \mathrm{kg}$, i.p.) and medetomidine (Pfizer, The Netherlands; $0.4 \mathrm{mg} / \mathrm{kg}$, i.p.). The lung resistance to the increasing doses of methacholine (acetyl- $\beta$-methyl-choline chloride, Sigma-Aldrich, The Netherlands; 0-25 mg/mL, 10\% puff/10 sec.) was measured by EMKA invasive measuring instrument of dynamic lung resistance and compliance (EMKA Technologies, France) $(1,3)$.

\section{Serum}

The lung function measurement was carried out on day 14. Blood was collected by cardiac puncture for measuring total serum $\operatorname{IgE}$ and mice were sacrificed with the overdose of pentobarbital injection intraperitoneally $\left(600 \mathrm{mg} / \mathrm{kg}, \mathrm{Nembutal}^{\mathrm{TM}}\right.$, The Netherlands). The blood was coagulated for $30 \mathrm{~min}$ at room temperature and centrifuged at $13,300 \mathrm{rpm}$ for $5 \mathrm{~min}$. Serum samples were stored at $-20^{\circ} \mathrm{C}$ until further use.

\section{Bronchoalveolar Lavage}

Lungs were gently lavaged with $1 \mathrm{ml}$ of pre-warmed pyrogenfree saline $\left(0.9 \% \mathrm{NaCl}, 37^{\circ} \mathrm{C}\right)$ containing protease inhibitor tablet (Complete Mini, Roche Diagnostics, Germany). The first lavage containing inflammatory cells was used for cytokines and chemokines measurements. Three additional lavages with $1 \mathrm{ml}$ of saline were carried out to maximize cell harvesting from the BALF. The BALF cells obtained from the 4 times lavaging, were centrifuged ( $400 \mathrm{~g}, 5 \mathrm{~min}$ ), and the pellets were pooled. The total numbers of cells were counted by the use of Bürker-Türk chamber. Afterward, cytospin preparations were made (centrifugation $20 \mathrm{~g}, 5 \mathrm{~min}, 4^{\circ} \mathrm{C}$ onto the glass) and stained by Diff-Quick method (Merz \& Dade A.G., Switzerland) to differentiate BALF cell counts. The number of macrophages, eosinophils, neutrophils, and lymphocytes was determined by light microscopy $(1,3)$.

\section{Preparation of Lung Homogenates}

The lungs were homogenized into the Precellys 24 tissue homogenizer tubes (Bertin Technologies, France) which contained $500 \mu \mathrm{l}$ of $1 \%$ Triton X-100 (Sigma-Aldrich) and PBS containing protease inhibitor (Complete Mini, Roche Diagnostics, Germany). The sample solutions were homogenized by using the homogenizer instrument three times for $10 \mathrm{~s}$. at $6,000 \mathrm{rpm}$ with a minimum of 2 min interruption period for cooling in between. The supernatant was collected, centrifuged at $14,000 \mathrm{rpm}$ for $10 \mathrm{~min}$ and stored at $-20^{\circ} \mathrm{C}$ for further experiments. Pierce BCA protein assay kit was used to determine the protein concentration of each sample according to the manufacturer's protocol (Thermo Fisher Scientific, USA). The homogenized samples were normalized to the concentration of $1 \mathrm{mg}$ protein $/ \mathrm{ml}(3,4)$.

\section{Cytokines Measurement}

The supernatants of the lung homogenates were assayed for the determination of cytokines and chemokine. IL-33 and CCL17 were measured via the package of DuoSet ELISA (R\&D Systems) and IL-13, IL-5, and total IgE were measured with a Ready-SETGo! ${ }^{\circledR}$ ELISA (eBioscience ${ }^{\text {TM }}$ (IL13, total IgE) and Invitrogen ${ }^{\text {TM }}$ IL-5, USA) kit. All ELISA assays were performed according to the manufacturer's protocol. The concentrations of the measured cytokines and chemokines were expressed as $\mathrm{pg} / \mathrm{mg}$ protein in lung homogenates and $\mathrm{pg} / \mathrm{mL}$ in serum. The ELISA plates were read at $450 \mathrm{~nm}$ using a Bio-Rad ELISA Reader (Bio-Rad, Hercules, CA, USA) $(3,4)$. 


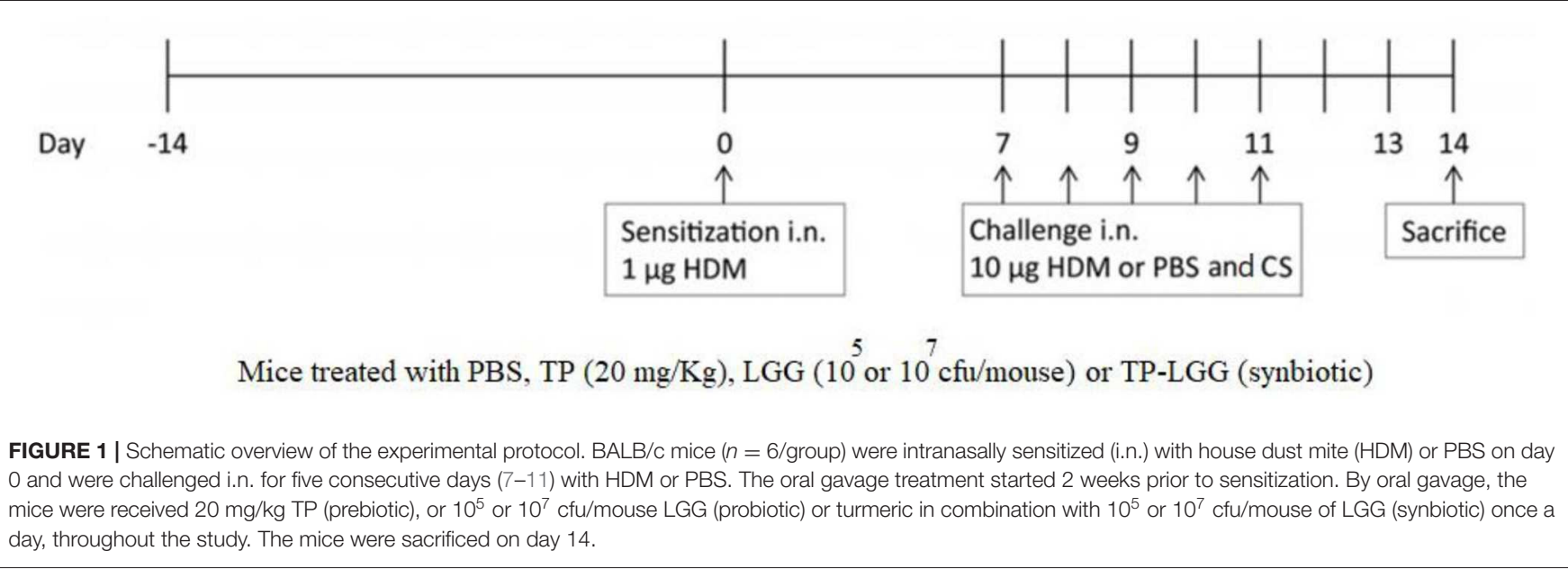

TABLE 1 | Summary of experimental platform grouping different conditions.

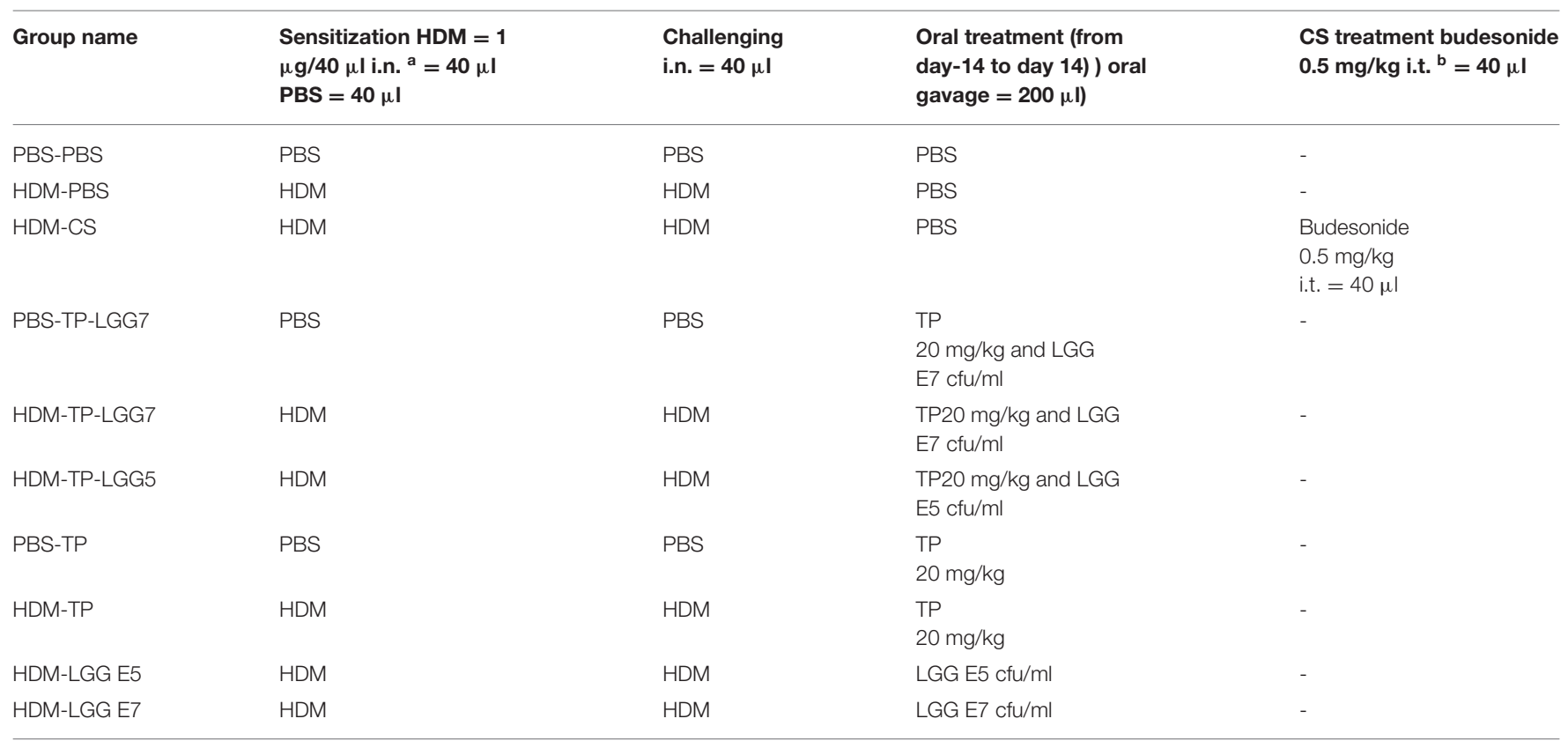

a.n., Intranasal.

bi.t., intratracheal.

\section{Flow Cytometric Analysis of Immune Cells in the Spleen}

Splenocyte cell suspensions were resuspended in PBS blocking buffer containing 1\% BSA and 5\% FCS (Sigma-Aldrich) and incubated for $15 \mathrm{~min}$ at $4^{\circ} \mathrm{C}$ with Fc block CD16/CD32 antibodies (BD Biosciences; $5 \mu \mathrm{g} / \mathrm{mL}$ ) to prevent non-antigenspecific binding. Cells $\left(5 \times 10^{5}\right)$ were subsequently stained with antibodies (eBioscience, The Netherlands, unless otherwise stated) against CD69-APC, CD4-PerCP Cy5.5, CXCR3-PE, T1ST2-FITC, ROR $\gamma$-APC, CD25-Alexa Fluor ${ }^{\circledR}$ 488, FoxP3PE Cy7, CD196-PE, and Fixable Viability Dye-eFluor ${ }^{\circledR} 780$ (eBioscience, USA) or matching isotype controls for $30 \mathrm{~min}$ at $4^{\circ} \mathrm{C}$. Cells were fixed using fixation buffer (eBioscience) or permeabilized for intracellular staining using the intracellular staining buffer set (eBioscience) according to the manufacturer's protocol. Flow cytometry was performed using FACS Canto II (BD Biosciences), and results were analyzed using Flowjo Software V. 10.6.2 (Becton Dickinson \& Company (BD). We used fluorescence minus one (FMO) to differentiate between negative and positive staining cell populations $(3,22)$.

\section{Statistical Analysis}

Results were represented as mean \pm standard error of the mean (SEM). Data were statistically analyzed using a one-way ANOVA and post-hoc Bonferroni's multiple comparisons test. Significance limits were set at $p \leq 0.05$. Statistical analysis was 
conducted using Graph Pad Prism software (version 7.04, Graph Pad Software, Inc.) $(19,22)$.

\section{RESULTS}

\section{Oral Administration of LGG (Probiotic), TP (Prebiotic), and LGG-TP (Synbiotic) Reduced Airway Hyperresponsiveness in HDM-Allergic Mice}

The EMKA lung function system was applied to detect airway hyperresponsiveness (AHR). The baseline resistance (0.90 \pm $0.05 \mathrm{~cm} \mathrm{H} \mathrm{H}_{2} \mathrm{O} /(\mathrm{ml} / \mathrm{sec}$ ) in PBS-PBS (negative control group) was similar between the experimental groups (Figure 2). Methacholine concentration-dependently increased airway resistance and was significantly enhanced in the HDM-PBS group [RL $1.87 \pm 0.06$ to $\left.4.38 \pm 0.05 \mathrm{~cm} \mathrm{H}_{2} \mathrm{O} /(\mathrm{mL} / \mathrm{sec})\right]$ compared to PBS-PBS group. Lastly, $1.56 \mathrm{mg} / \mathrm{mL}$ of methacholine caused a significant difference between PBS-PBS and HDM-PBS groups $(\mathrm{p}<0.05)$. The airway hyperresponsiveness of the mice receiving either $20 \mathrm{mg} / \mathrm{kg} \mathrm{TP}$ (HDM-TP) or $10^{5} \mathrm{cfu} /$ mouse of LGG was significantly decreased at $25 \mathrm{mg} / \mathrm{mL}$ of methacholine (Figure 2), while the synbiotic (HDM-TP-LGG E7) seems to be the most effective and started to alleviate hyperresponsivity from lower concentration of methacholine $(12.5 \mathrm{mg} / \mathrm{mL})$ (Figure 2). A consistent decrease was observed in the HDM-CS group although the values did not reach statistical significance (Figure 2).

\section{Oral Administration of LGG, TP, and LGG-TP Reduced Inflammatory Cells in BALF of HDM-Allergic Mice}

Accumulation of inflammatory cells in the lung occurs as the result of airway inflammation in asthma. The bronchoalveolar lavage fluid (BALF) was analyzed regarding the inflammatory cell influx into the airways of control and treatment groups (Figure 3). The total number of BALF cells was increased in the mice sensitized with HDM (HDM-PBS) compared to PBS-PBS group (Figure 3A). This increase was mainly due to eosinophils (Figure 3C) compared to the control group $(\mathrm{p}<0.05)$. The same trend was observed for macrophages (Figure 3B), neutrophils (Figure 3E) and lymphocytes (Figure 3D) but it was not statistically significant. Importantly, the probiotic, prebiotic, and synbiotic intervention significantly reduced the cell infiltration in the BALF ( $\mathrm{p}<0.05$ which was mainly due to a reduction in eosinophils $(2,3)$. The number of eosinophils was significantly reduced in the HDM-CS group ( $\mathrm{p}<0.05)$.

\section{Effect of Oral Administration of LGG, TP, and LGG-TP on the Attenuating of Th2-Type Mediators in Lungs and IgE Levels in Serum of HDM-Allergic Mice}

The $\mathrm{Th}_{2}$ cytokines that play an important role in allergic asthma, like IL-5, IL-13, CCL17, and IL-33 along with total IgE in serum were measured. The mentioned cytokines and chemokine were significantly increased in the lung homogenates of HDM-PBS compared to the PBS-PBS control group.

Oral administration of $20 \mathrm{mg} / \mathrm{kg} \mathrm{TP}$, different doses of LGG $\left(10^{5}\right.$ or $\left.10^{7} \mathrm{cfu} / \mathrm{mouse}\right)$, and their combination as a synbiotic mixture (containing $10^{5} \mathrm{cfu} /$ mouse of LGG and $20 \mathrm{mg} / \mathrm{kg} \mathrm{TP}$ ) could significantly reduce the concentration of IL-5 in the lung homogenates (Figure 4A). There was also a positive correlation between the IL-5 concentration and number of eosinophils in the BALF (Figure 4B, r $=0.9276, \mathrm{p}=0.01$ ). In contrast to Budesonide, the synbiotic mixtures and TP could considerably diminish IL-13 levels in the lung homogenates compared to HDM-PBS group as well (Figure 4C). The chemokine CCL17, which contributes to the $\mathrm{Th}_{2}$ cell recruitment in asthma, was elevated in HDM-PBS group compared to PBS-PBS group ( $\mathrm{p}$ $<0.05)$. Both TP and synbiotic $\left(10^{5} \mathrm{cfu} /\right.$ mouse of LGG and 20 $\mathrm{mg} / \mathrm{kg} \mathrm{TP}$ ) significantly suppressed the chemokine level and the same trend was observed for $10^{5}$ LGG ( $\left.p>0.05\right)$ (Figure 4D). Sensitization with HDM increased the concentration of IL-33, a $\mathrm{Th}_{2}$-driving mediator, in the lung homogenates. All treatments tended to suppress IL-33 levels in the HDM groups which was not significant (Figure 4E). There was a notable total IgE increase in the HDM-PBS compared to PBS-PBS mice which was suppressed significantly in the group treated with synbiotic (HDM- LGG E5) $(\mathrm{p}<0.05)$ (Figure 4F) $(1-4)$.

\section{Effect of Oral Administration of LGG, TP, and LGG-TP on Relieving of Maximum Fluorescent Intensity of Th2 and T17 in Splenocytes}

Splenocytes were analyzed for $\mathrm{T}$ cell populations (Figure 5D). The abundance of Th2 and Th17 was significantly increased in asthmatic mice compared to control group (Figures 5A,B). All of the treatments significantly relieved the frequency of Th2 cells. This result is in accordance with the efficiency of LGG, TP and synbiotics in reducing CCL17 chemokine which is implicated in attracting Th2 cells in airways (Figure 4D). It is also elicited from the results that the synbiotics, also TP could significantly decrease the intensity of $\mathrm{ROR} \gamma^{+} \mathrm{CD} 4^{+} \mathrm{Th} 17$ cells. The attenuation of Th2 and Th17 cells by pro- pre- and synbiotics was not followed by a shift toward a more Th1 cells immune response (Supplementary Figure 1 ). The results also show the $\mathrm{CD} 25^{+}$Foxp $3^{+}$Treg tended to increase in the synbiotic groups compared to asthmatic group but this was not significant (Figure 5C). The entire of gating strategy has been displayed in Supplementary Figure 2.

\section{Superior Effect of Synbiotic in Comparison With Probiotic and Prebiotic in Alleviating the Inflammation}

According to the results, the synbiotic significantly started to suppress airway hyperresponsiveness from a lower concentration of methacholine (Figure 2).

Besides, the mice received TP (HDM-TP) or the synbiotic combination with $10^{5} \mathrm{cfu} /$ mouse LGG (HDM-TP-LGG E5) decreased IL-5, IL-13, and CCL17 (Figures 4A,C,D) even more than other treatments. It is also interpreted from the results 


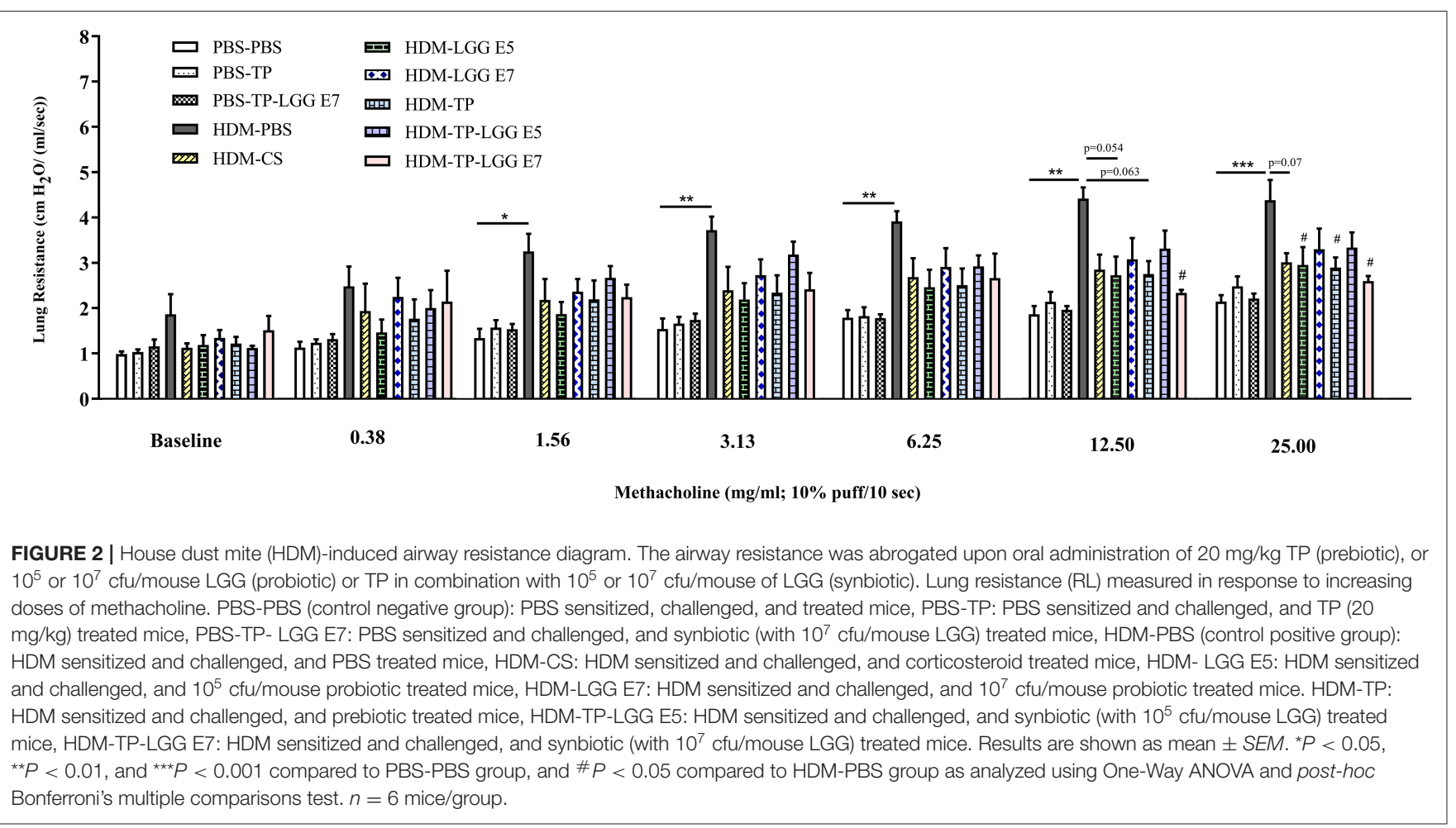

that the synbiotics (HDM-TP-LGG E5 or HDM-TP-LGG E7) clearly displayed a superior effect than the probiotics to reduce the concentrations of Th2-mediated cytokines such as IL-5 and IL-13 and DC-mediated chemokine CCL17 (Figure 6). This reduction was accompanied by downregulation of activated Th2 cells $\left(\mathrm{CD} 9^{+} \mathrm{T}_{1 S T 2}{ }^{+} \mathrm{T}\right.$ cells) and Th17 (CD169 ${ }^{+}$Ror ${ }^{+}$cells). It is also explicit that the synbiotic (HDM-TP-LGG E7) was able to significantly elevate the $\mathrm{CD} 25^{+}$Foxp $3^{+}$Treg compared to probiotic (HDM-LGG E7).

\section{DISCUSSION}

In the present study, we demonstrated for the first time, that the oral administration of Lactobacillus rhamnosus GG, TP, and their combination alleviated the allergic airway inflammation in HDM-induced murine model of asthma. However, all of the treatments (probiotics, prebiotics, and synbiotics) showed suppressive effects on lung function and airway inflammation along with Th2 related cytokines, Th2, and Th17 cells, but we illustrated synbiotic works more effective in comparison with other treatments alone.

Recent studies have consistently begun to elucidate the interaction between gut microbiome function and the immune system response. These researches invested to discover the possible mechanisms by which the resident bacteria can modulate Th2 allergic immune response. However, little is known about the contribution of the molecules secreted by probiotic bacteria (such as SCFA) to act as immune regulators. There is an interplay between prebiotics and probiotics, for example, prebiotics are able to support probiotics growth and lifespan. These findings highlight the need for further investigation on synbiotic mixtures $(11-13,15,23)$.

Airway hyperresponsiveness (AHR) is one of the key clinical features of asthma. In this study, HDM-LGG E5 and TP could reduce AHR individually, however, the synbiotic mixture (HDM-TP-LGG E7) demonstrated more potent suppressive effects. In fact, the synbiotic mixture started a reduction of airway hyperresponsiveness in the lower concentration of methacholine $(12.5 \mathrm{mg} / \mathrm{ml})$ with a greater impact $(p<0.02)$. This indicates that Lactobacillus rhamnosus GG and TP might be able to synergize each other. Moreover, as a standard treatment budesonide treatment showed a decreasing trend in mitigating lung resistance (Figure 2).

The observed contribution of the probiotic, prebiotic and synbiotic is in line with Verheijden et al. who found that the administration of long-chain fructooligosaccharide (lcFOS) combined with Bifidobaterium breve M-16V suppressed lung resistance and airway inflammation in allergic mice (22). Vos et al. also showed that a specific oligosaccharide mixture containing short chain galactooligosaccharide (scGOS) and lcFOS (scGOS-lcFOS) could alleviate the lung resistance and BALF inflammatory cells in the ovalbumin (OVA)-induced model of asthma (24). The same combination (scGOS-lcFOS) together with Bifidobaterium breve M-16V was used by Sagar et al. (25). They demonstrated that the synbiotic mixture significantly reduces the percentage of BALF total inflammatory cells and eosinophils in a murine model of chronic asthma, which is consistent with our findings. In another study, combination of immunofortis (prebiotic mixture) and Bifidobaterium breve $\mathrm{M}-16 \mathrm{~V}$ could dampen anaphylactic symptom scores 

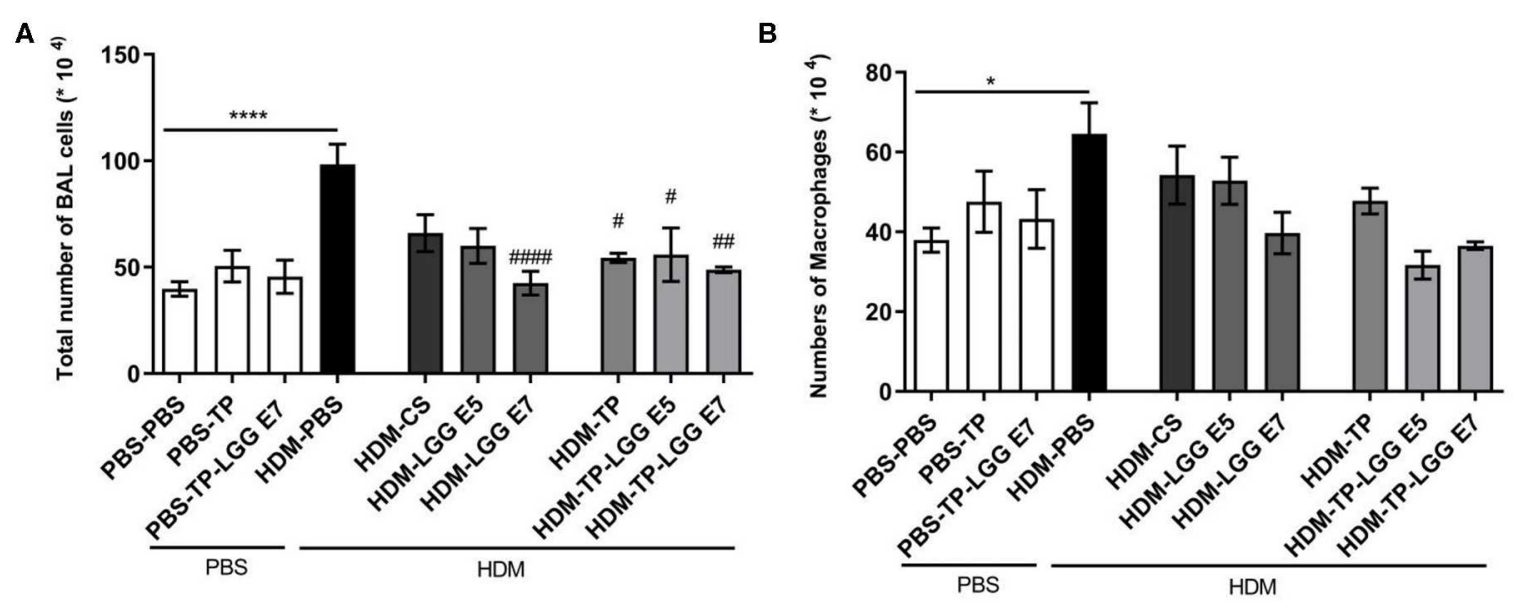

C

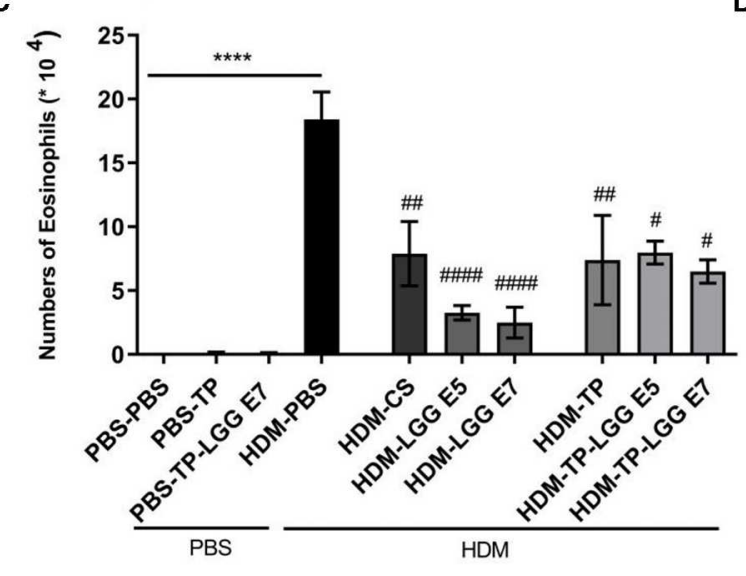

E

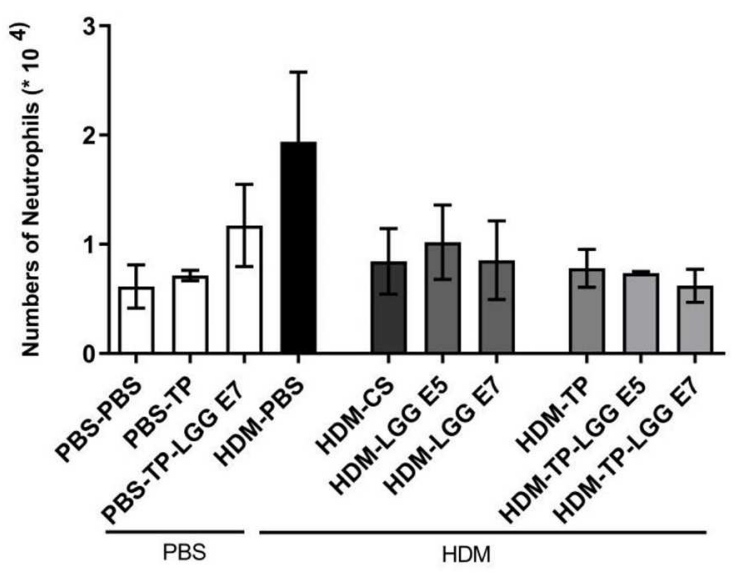

FIGURE 3 | Differential inflammatory cell count of bronchoalveolar lavage fluid (BALF). (A) Total BALF cells, (B) the absolute number of macrophages, (C) eosinophils, (D) lymphocytes and, (E) neutrophils. Data are shown as mean \pm SEM, $n=6$ mice/group. ${ }^{*} P<0.05$ and ${ }^{* \star * *} P<0.0001$ compared to PBS-PBS group,

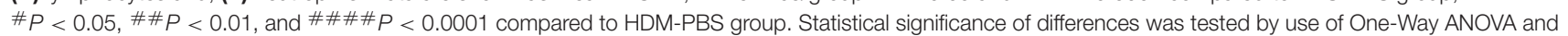
post-hoc Bonferroni's multiple comparisons test.

and allergic skin response, which was stronger compared to the individual effects of the pro- and prebiotic alone. The so-called immunofortis and Bifidobaterium breve $\mathrm{M}-16 \mathrm{~V}$ could also reduce asthma-like manifestations in infants with atopic dermatitis (26). There is a number of studies related to the anti-inflammatory potential of Lactobacillus rhamnosus 
A

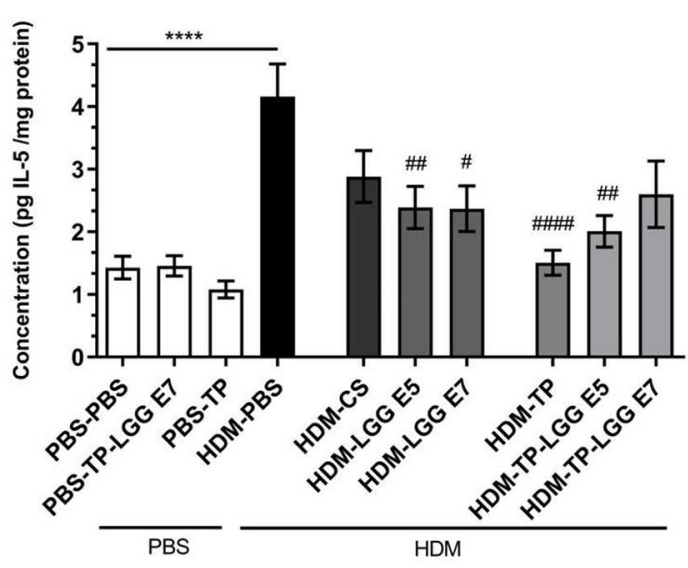

C

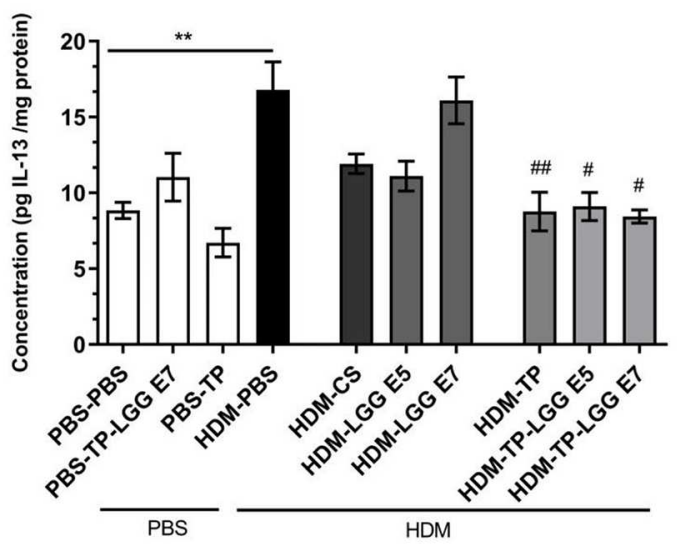

$\mathbf{E}$

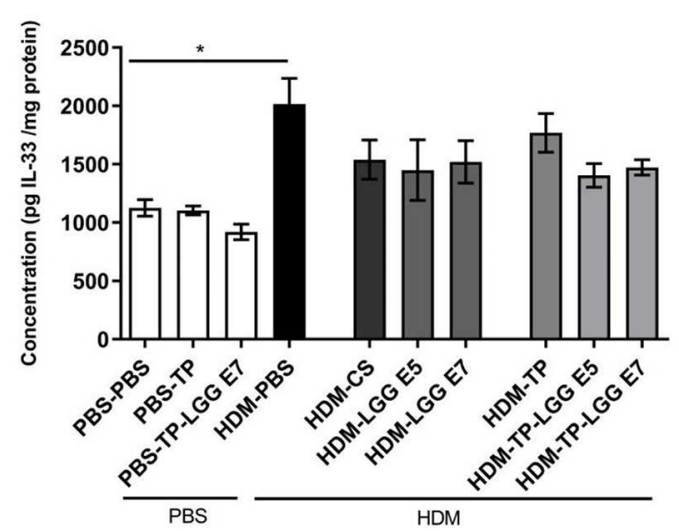

B

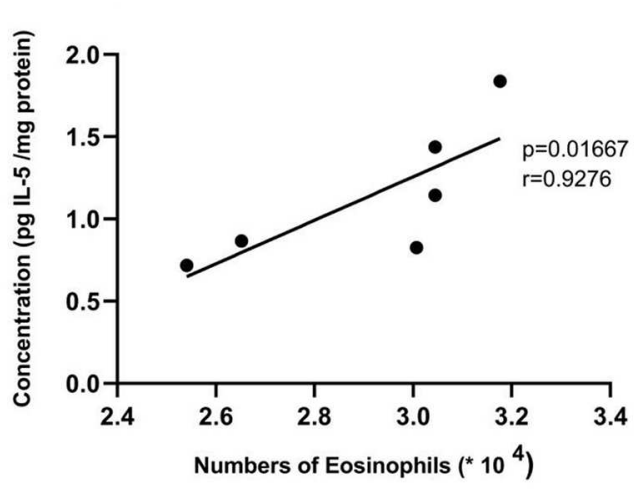

D

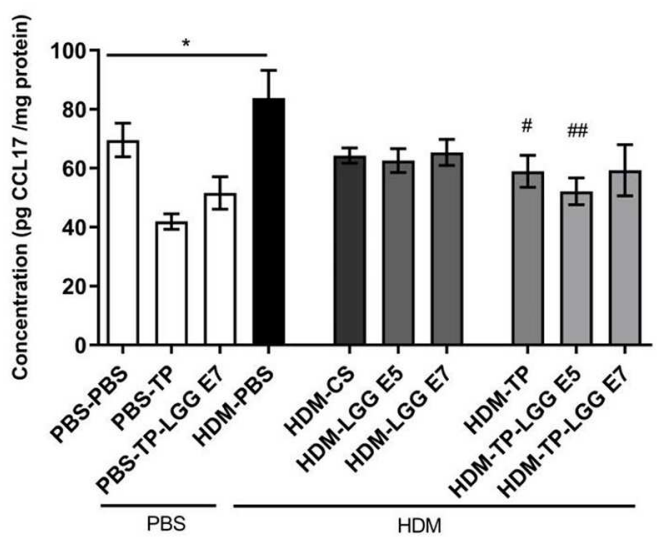

$\mathbf{F}$

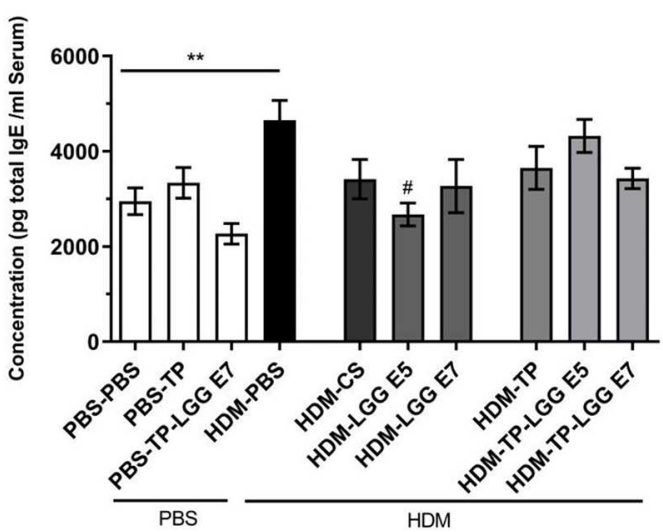

FIGURE 4 | Immune-related mediators' measurements. IL-5, IL-13, IL-33, CCL17, and total IgE concentrations were measured in supernatant of lung homogenates (pg/mg protein) and in serum for Total IgE in HDM-allergic mice. IL-5 (A), IL-5-eosinophils correlation (B), IL-13 (C), CCL17 (D), IL-33 (E), and total IgE (F). Data are shown as mean $\pm S E M, n=6$ mice/group. ${ }^{\star} P<0.05,{ }^{\star \star} P<0.01$, and ${ }^{\star \star \star \star} P<0.0001$ compared to PBS-PBS group, $\# P<0.05$, \#\#P<0.01, and

$\# \# \# \# P<0.0001$ compared to HDM-PBS group. Statistical significance of differences was tested by use of One-Way ANOVA and post-hoc Bonferroni's multiple comparisons test.

GG and Bifidobaterium breve M-16V. Both strains, as well as synbiotic combination of Bifidobaterium breve $\mathrm{M}-16 \mathrm{~V}$ and scGOS-lcFOS decreased eosinophils and neutrophils in BALF in ovalbumin-exposed mice $(1,25,26)$. LGG alone or along with the other bacterial species and prebiotics (galactooligosaccharides, fructooligosassharides) effectively relieved ovalbumin-induced asthma in mice. Given the striking effect of LGG on lung function $(2,27,28)$, its combination with 

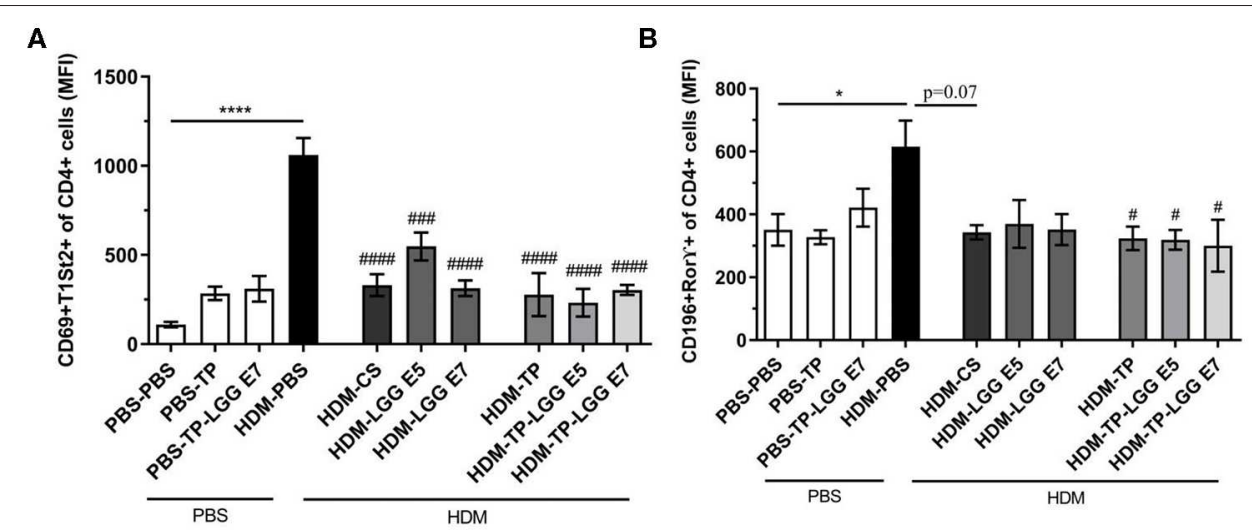

C

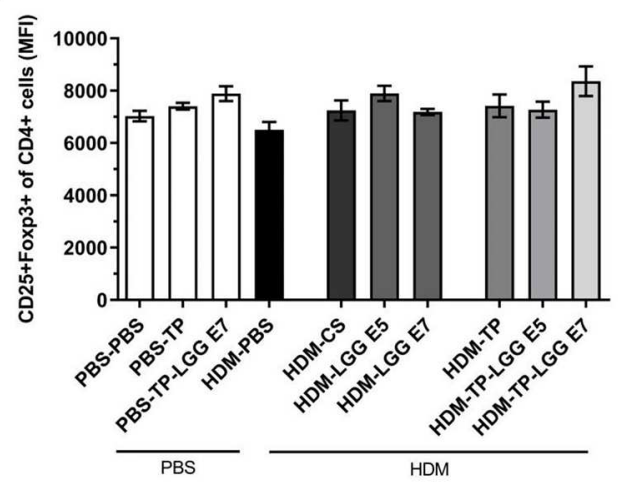

D
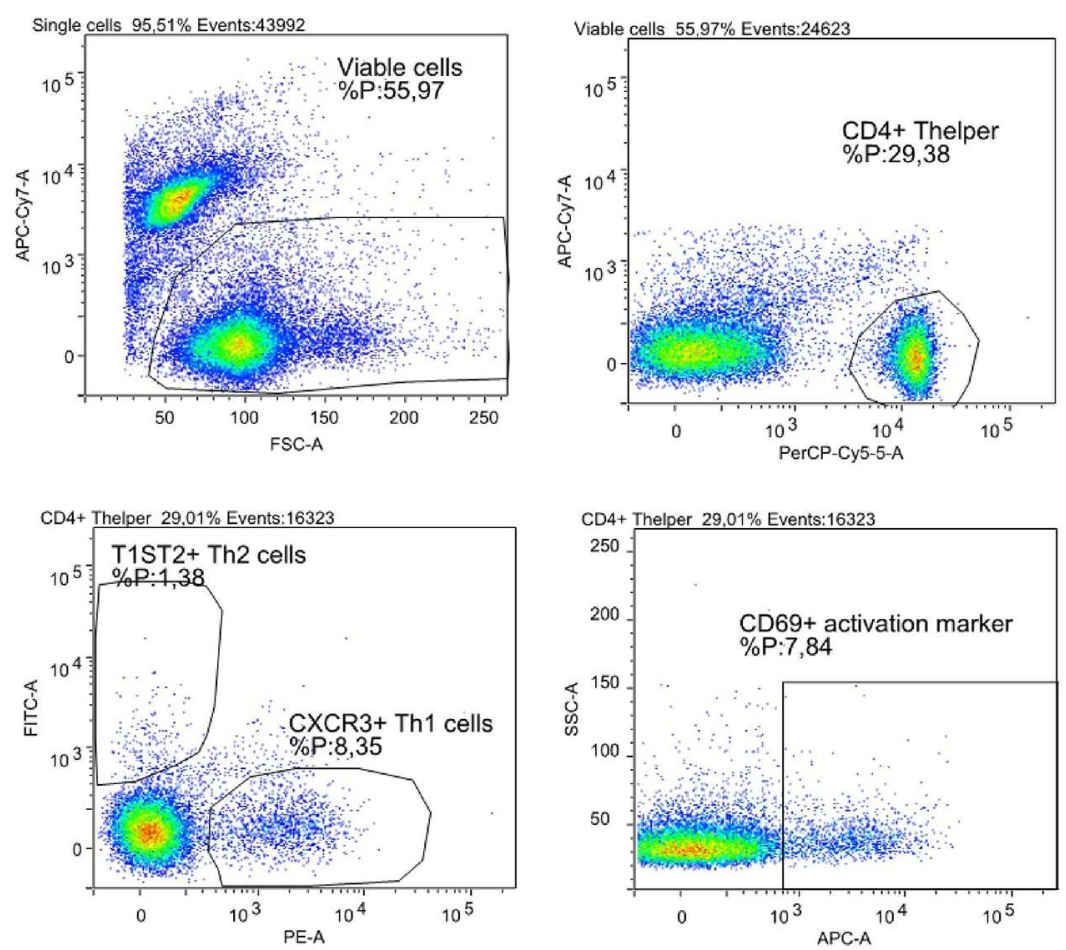

FIGURE 5 | The flowcytometry diagram of T cells subsets. Splenocytes T cell subsets. (A) The MFI of Th2 cells (CD69+ T1ST2+ of CD4+ cells), (B) Th17 cells $\left(\mathrm{CD} 196^{+} \mathrm{ROR} \gamma+\right.$ of $\mathrm{CD} 4^{+}$cells), (C) regulatory T cells (Tregs) (CD25+ $\mathrm{FoxP}^{+}$of $\mathrm{CD} 4^{+}$cells) was analyzed in spleen cell suspensions, and (D) gating strategy. Values were reported as maximun flourscence intensity (MFI). Data are shown as mean $\pm S E M, n=6$ mice/group. ${ }^{\star} P<0.05$ and ${ }^{\star \star \star \star} P<0.0001$ compared to PBS-PBS

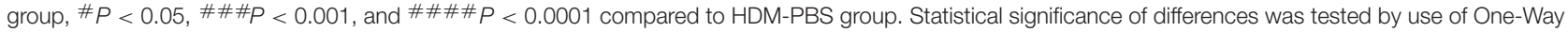
ANOVA and post-hoc Bonferroni's multiple comparisons test. 


$$
\text { A }
$$

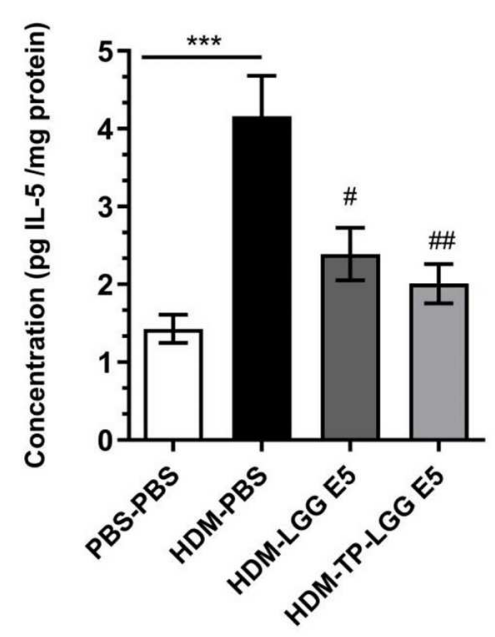

C

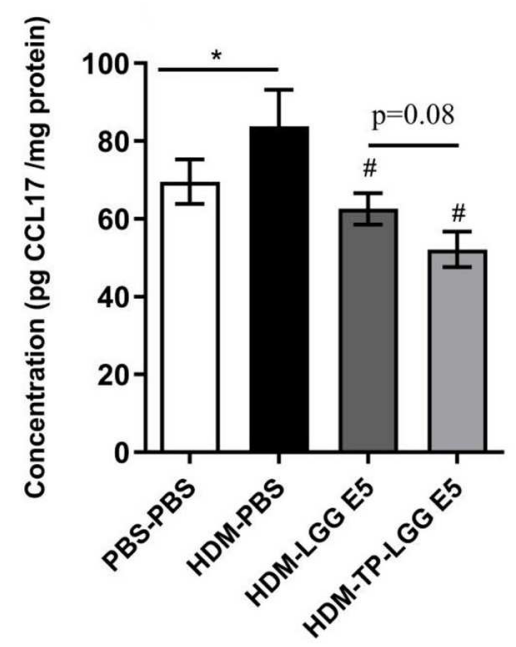

E

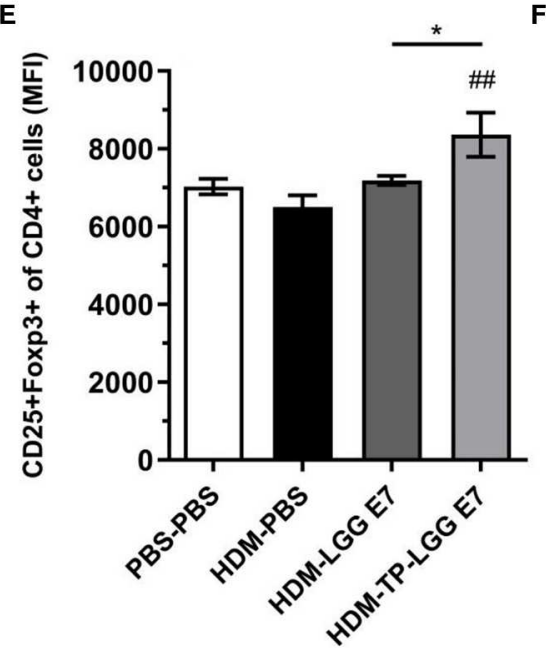

B

D
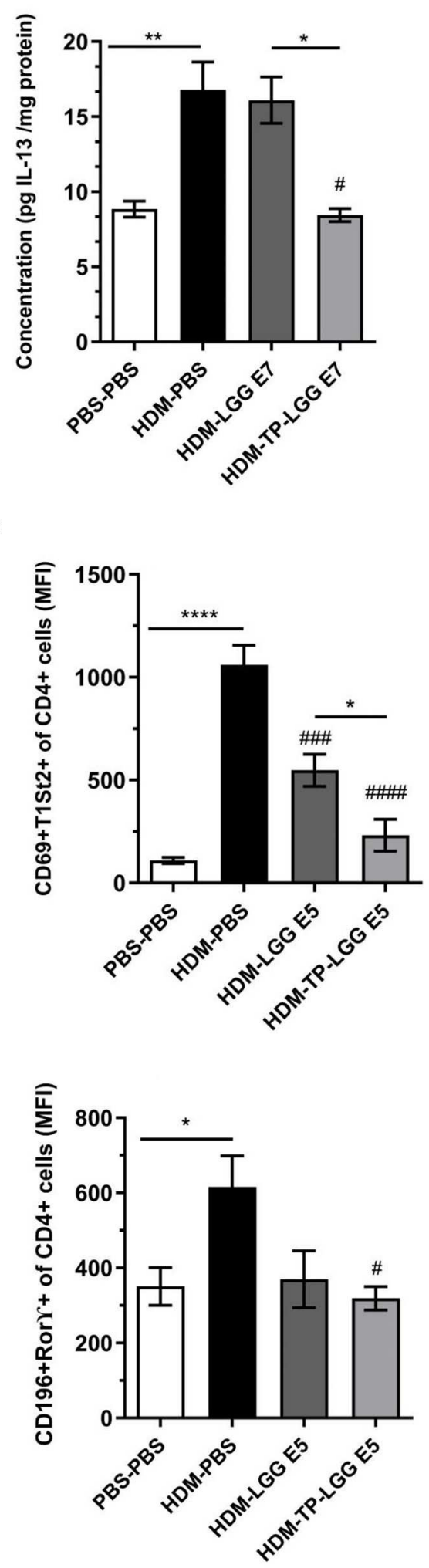

FIGURE 6 | Superior effect of Synbiotic than either of probiotic and prebiotic measurement. IL-5 (A), IL-13 (B), CCL17 (C), CD4+Th2 cells (D), CD25+FoxP3+Treg (E), and $\mathrm{CD}_{196}{ }^{+} \mathrm{ROR} \gamma+\mathrm{Th} 17 \mathbf{( F )}$. Values were reported as maximun flourscence intensity (MFI). Data are shown as mean $\pm S E M, n=6$ mice/group. ${ }^{*} P<0.05,{ }^{* *} P$

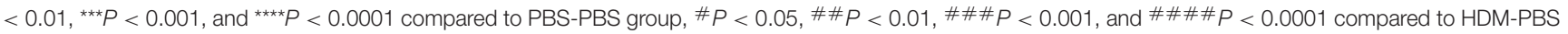
group. Statistical significance of differences was tested by use of One-Way ANOVA and post-hoc Bonferroni's multiple comparisons test. 
turmeric even unveiled more potent effects than any of the individuals. In our study, inhibition of AHR by the synbiotic mixture was associated with the reduced inflammatory cells and cytokines, which might be due to flavonoid components in turmeric possessing powerful anti-allergic properties $(19,29,30)$.

In most asthmatic patients, the main cells infiltrated in the lungs are eosinophils, neutrophils, and lymphocytes $(18,31)$, accumulating in the bronchioles and augment airway inflammation. Among the inflammatory markers involved in asthma, eosinophils orchestrate the paramount inflammatory responses, including airway hyperresponsiveness, mucus secretion of epithelial cells, and allergic cytokines production. Recent data show that eosinophils also participate in airway remodeling $(18,32)$. We showed that the total inflammatory cells in the BALF were significantly increased in HDM-PBS asthmatic mice compared to PBS-PBS control mice. Oral administration with LGG, TP, and synbiotic mixture markedly decreased the total inflammatory cell numbers into BALF. However, TP with LGG (synbiotic) did not really show a superior effect relative to LGG or TP alone. Probably, a maximum plateau is reached, and a further decrease might be possible in combination with glucocorticosteroids. It is known that there is a correlation between reduction of inflammatory cells in the lung and suppression of Th2 associated cytokines (33-35). Consistent with this, we found the reduction of eosinophils in mice treated with TP, LGG, and synbiotic mixture, which was associated with a decrease in IL-5, IL-13, and IL-33 production.

Allergic asthma is related to a Th1/Th2 imbalance with increased Th2 cytokines production (18). HDM triggers inflammation in airway epithelial cells (AECs), which consequently activates pattern recognition receptors (PRRs), in particular, Toll-like receptors (TLRs) $(36,37)$. Interaction between HDM and AECs is the central point of sensitization phase recruiting inflammatory cells to the airway submucosa. Subsequent exposure to HDM (challenge phase) augments the production of IL-33, CCL17, TSLP, IL-25, and different chemokines causing clinical manifestations.

Many investigations showed that the concentration of CCL17, IL-33, CCL20, and CCL22 were increased in the airways of asthmatic patients compared to healthy individuals $(32,38-40)$. The concentration of IL-5 and CCL17 showed a decreasing trend in synbiotic (HDM-TP-LGG E5) and prebiotic group. CCL17 is mainly responsible for recruiting and activating neutrophils to the lungs (41). The falling trend of neutrophils in the BALF and CCL17 in the lung homogenates was found in asthmatic mice treated with synbiotic (HDM-TP-LGG E5) and prebiotic alone compared to the HDM-PBS group (Figures 3E, 4D). The Synbiotic with $10^{5} \mathrm{cfu} / \mathrm{ml}$ of LGG displayed a better suppressive effect than the probiotic (HDM-LGG E5) while the other synbiotic could not demonstrate the same effect (data not shown) (Figure 6C). This phenomenon can be attributed to the so-called compatibility of probiotic and prebiotic which seems to be a key factor in synbiotic proficiency. IL-13 was another pivotal mediator which the synbiotics could impact on. In this regard, HDM-TP-LGG E7 was significantly more effective than the probiotic in lowering IL-13 (Figure 6B).
IL-33 activates DCs and attracts Th2 cells in the course of Th2 responses $(35,42,43)$. Clinically, in the biopsies of asthmatic patients, the vigorous increase of IL-33 has been observed compared to healthy people (44). Here we also showed a high level of IL-33 in the lung homogenates of asthmatic mice compared to non-asthmatic groups $(p<0.05)$. The synbiotics showed a reduction trend of IL-33 level rather than other treatments, however, the reduction was not statistically significant (Figure 4E).

The exact underlying mechanisms by which TP, LGG or synbiotic ameliorate inflammation remain unclear and need further exploration. In this study, we made an attempt to review some of the known characterized mechanisms. Several pieces of evidence indicate that the dysbiosis in the intestinal microbiota composition is associated with respiratory disorders. In many studies the considerable reduction in the abundance of bifidobacteria and lactobacilli genera has been found in asthmatic patients compared to healthy controls (45). The gut dysbiosis also encourages inflammation through the growth of Enterobacteriaceae and the decrease of Lactobacilli and Lactococci (46). Colestridia, Haemophilus, Streptococcus, and Moraxella species have also been correlated with elevated risk of asthma exacerbations (47). Some bacterial species especially Lactobacillus rhamnosus GG can stimulate naive $\mathrm{T}$ cells to be differentiated to peripheral Treg (48). The commensal bacteria along with lactobacilli and bifidobacteria are able to turn down Th2 cell differentiation by producing special metabolites such as short-chain fatty acids $(26,45)$. In line with these studies, our findings show that the probiotic could shift the naïve $\mathrm{T}$ cells to Treg, however the synbiotic indicated more potency to increase Tregs intensity (Figure 6E). Besides, the ability that the synbiotic was more remarkable in downregulating Th2 cells compared to either asthmatic group or probiotic (Figure 6D). Several evidences show the effect of gut microbiota and herbal components are due to the SCFA production $(7,49-51)$. Many studies also indicate that the enhanced effectiveness of synbiotic above either of the constituents (probiotic and prebiotic) is due to the production of SCFA, this implies that there is a need to measure the concentration of SCFA produced by pro-, pre- and, synbiotic in further studies to unravel the mechanism (52).

One of the mechanisms by which SCFAs regulate the immune responses is to enhance the $\mathrm{CD}_{103}{ }^{+} \mathrm{DCs}$ of MLNs and subsequently increase the activity of retinal dehydrogenase 2(RALDH2) in $\mathrm{CD}_{103}{ }^{+}$DCs. The conversion of Vitamin A to retinoic acid which is mediated by RALDH2 stimulates Treg cells generation (48). In line with this study, our combination therapy (HDM-TP-LGG E7) significantly increase Treg compared to the TP and LGG alone which is presumably due to the concentration of SCFA produced by LGG when is together with turmeric. The other mechanism could involve in $G$ protein-coupled receptor 41 (GPR41, also called free fatty acid receptor 3 or FFAR3) (53). SCFA may elicit their regulatory functions through binding to this protein which may impair the capacity of DCs to stimulate Th2-mediated immune responses (54). Given that the production of SCFA propionate, acetate and butyrate depends on indigestible carbohydrate fermentation, the role of prebiotics in immune response regulation are revealed. 
Th17 cells, characterized by the retinoic acid-related orphan receptor $\curlyvee$ (ROR $\curlyvee$ ) marker, which is a main transcription factor mediating the Th17 differentiation, can stimulate tissue inflammation, and neutrophil recruitment (55). Recent findings have suggested that Th17 cells and its mediated cytokines were implicated in the pathogenesis of allergic asthma. The results indicate our synbiotics and prebiotic significantly reduced $\mathrm{CD}_{196}{ }^{+} \mathrm{ROR} \Upsilon^{+}$Th17 cells frequency compared to asthmatic group (Figures 5B, 6F). The marker CD196 also called chemokine receptor 6 (CCR6), and its ligand CCL20, contributes to the recruitment of Th17 cells and Th2 cells to the injured tissue and specially deal with the asthma exacerbation. Since the airway responsiveness was relieved in CCR6-deficient mice, CCL20-CCR6 axis could be a putative approach for the asthma therapy (56).

The first line of allergic inflammation is the elevation of IL33, which is mainly expressed by HDM injured lung epithelial cells (Figure 7). IL-33 is also a chemo-attractant for Th2 cells to the inflammation site $(35,42,43)$. Synbiotic intervention tended to reduce the concentration of IL-33. The IL-33 secretion along with the allergen stimulation can activate ILC2 and DCs. Activated DCs are able to polarize naïve T helpers to Th2 in the CCL17 saturated environments (57). Our treatments specially
HDM-TP-LGG E5 proficiently mitigate the concentration of CCL17 leading to the decreasing of Th2 frequency (Figure 7). On the other hand, ILC2 together with Th2, secrete IL-13, IL-5, and IL-4 which in turn differentiates B cells to IgE producing plasma cells $(58,59)$. Probiotic, prebiotic, and synbiotic interventions significantly lessened IL-5 and IL-13 production. This effect was more striking in synbiotic groups (Figure 7). Beyond this effect on Th2-mediated cytokines, the combination therapies also

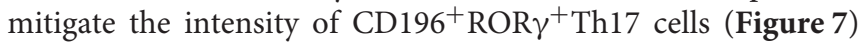
which is known to be elevated in asthmatic peoples (57). Our treatments specially probiotics reduces the number of eosinophils in BALF. As far as we know, the mechanism of our pro-, pre, and synbiotic in Th2 suppression is independent to the Th1 since HDM sensitization and challenge did not affect the frequency of Th1 and even combination treatment could not affect it.

Our study not only strengthens the previous evidence regarding the beneficial effects of probiotics and prebiotics in the suppression of allergic responses but also suggests that their combination (a synbiotic) might have a superior effect than any of each treatment alone. In this study, we sensitized the mice with HDM and then treated with PBS, LGG, TP, and synbiotics orally during the exposure of HDM and evaluated the lung hyperresponsiveness to the different doses of methacholine. We

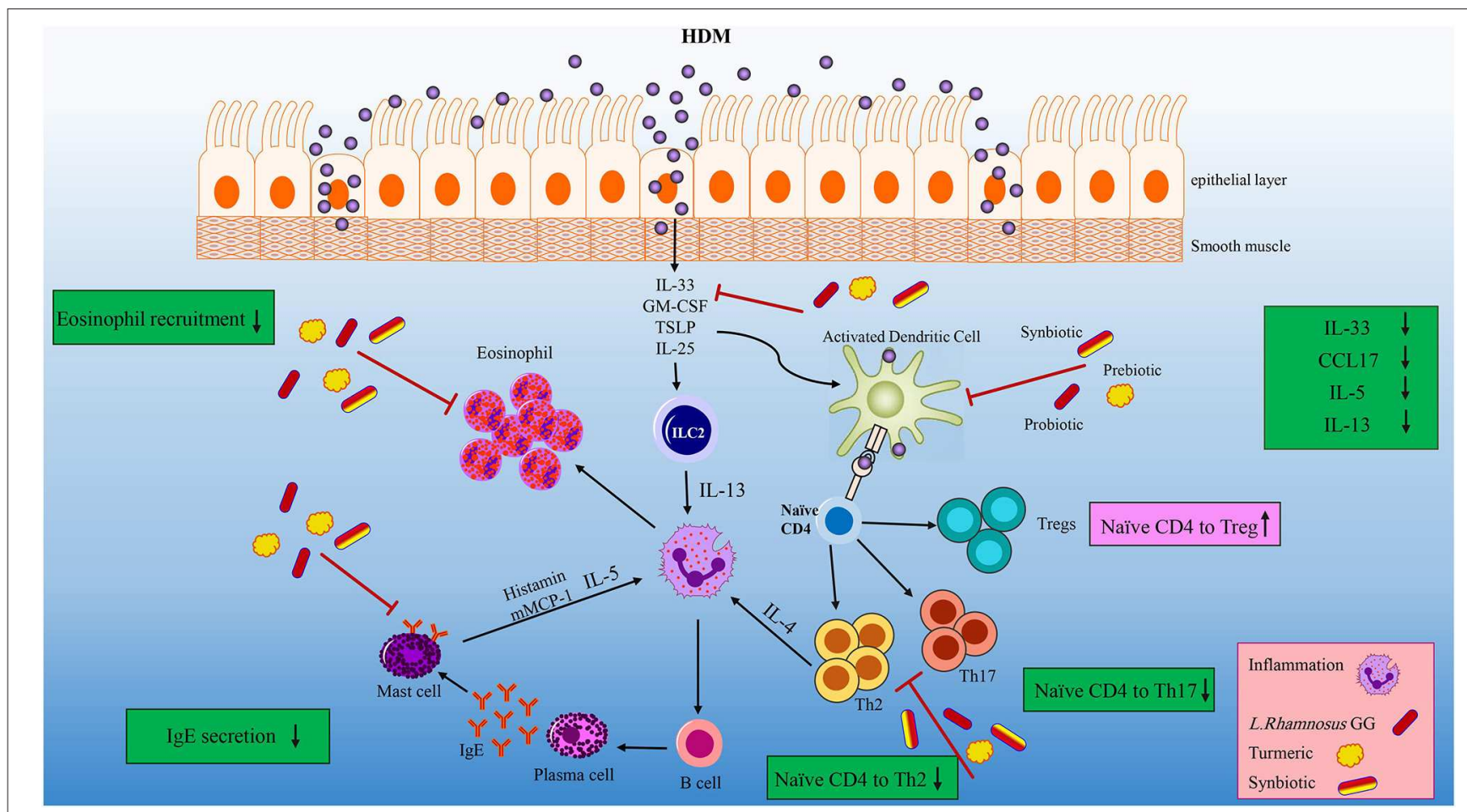

FIGURE 7 | Overview of the effects of the LGG, TP and synbiotic treatment on HDM-induce murine model of asthma. After the initial exposure to HDM IL-33, GM-CSF, TSLP and IL-25 is released by damaged tissue, and IL-33 activate DCs and ILC2. CCL17 are proliferated by activated DC, which can polarize naïve T cells into Th2 cells. LGG, TP or combination therapy tended to reduce CCL17 and IL-33 concentrations, leading to decrease DCs activation. Beyond their effect on suppressing DC-related cytokine and chemokine, they reduced the differentiation of naïve T cells to Th2 cells significantly. ILC2 cells as well as Th2 cells have the ability to produce IL-4, IL-5, and IL-13. Concentrations of IL-5 and IL-13 were reduced after specifically synbiotics treatment. The number of eosinophils reduced by all treatments specially $10^{5} \mathrm{cfu} / \mathrm{ml}$ LGG. All treatments could significantly reduce the Th2 and Th17 frequency. This reduction was more remarkable in HDM-TP-LGG E5 compared to asthmatic and probiotic group. On the other hand, the Treg frequency showed an elevation in HDM-TP-LGG E7 compared to asthmatic and probiotic group. 
also measured the number of inflammatory cells in the BALF and concentration of cytokines and a chemokine which are responsible for allergic manifestation.

The present study has assessed the modulatory effects of pre, pro, and synbiotic on allergic airway inflammation at the cellular level. However, more broadly, research is needed to determine the signaling pathways by which the combination therapy suppresses the inflammatory cascade. The exploring short chain fatty acids produced by LGG with/without TP, characterization the probable components released by LGG like SCFA, and interaction between TP and LGG also need to be considered as further investigations. It is also worthwhile to optimize the repetition times and the duration of the treatment that lasts long effect on the body. In addition, the other factors which determine the optimal efficacy of a synbiotic, are 1) the duration of prebiotic and probiotic reciprocal interaction and 2) the ability of probiotic to be implanted into the gut, thus optimizing these factors can be highly essential for development of food-based remedy.

\section{DATA AVAILABILITY STATEMENT}

The raw data supporting the conclusions of this article will be made available by the authors, without undue reservation, to any qualified researcher.

\section{ETHICS STATEMENT}

This study was carried out in strict accordance with the recommendations in the Guide for the Care and Use of the Dutch Committee of Animal Experiments (Utrecht, the Netherlands). The protocol was approved by the Committee on the Ethics of Animal Experiments of the Utrecht University (Protocol Number: 1080020174426). All surgery was performed under

\section{REFERENCES}

1. Sagar S, Morgan ME, Chen S, Vos AP, Garssen J, van Bergenhenegouwen J, et al. Bifidobacterium breve and Lactobacillus rhamnosus treatment is as effective as budesonide at reducing inflammation in a murine model for chronic asthma. Respir Res. (2014) 15:46. doi: 10.1186/1465-992115-46

2. Wu C, Chen P, Lee Y, Ko J, Lue K. Effects of immunomodulatory supplementation with Lactobacillus rhamnosus on airway inflammation in a mouse asthma model. J Microbiol Immunol Infect. (2016) 49:62535. doi: 10.1016/j.jmii.2014.08.001

3. Verheijden KAT, Willemsen LEM, Braber S, Leusink-Muis T, Jeurink PV, Garssen J, et al. The development of allergic inflammation in a murine house dust mite asthma model is suppressed by synbiotic mixtures of nondigestible oligosaccharides and Bifidobacterium breve M-16V. Eur J Nutr. (2016) 55:1141-51. doi: 10.1007/s00394-015-0928-8

4. Verheijden KA, Willemsen LE, Braber S, Leusink-Muis T, Delsing DJ, Garssen J, et al. Dietary galacto-oligosaccharides prevent airway eosinophilia and hyperresponsiveness in a murine house dust mite-induced asthma model. Respir Res. (2015) 16:17. doi: 10.1186/s12931-015-0171-0

5. Yun X, Shang Y, Li M. Effect of Lactobacillus salivarius on Th1/Th2 cytokines and the number of spleen $\mathrm{CD} 4^{+} \mathrm{CD}_{2} 5^{+}$Foxp3 ${ }^{+}$Treg in asthma Balb/c mouse. Int J Clin Exp Pathol. (2015) 8:7661-74.

6. Blümer N, Sel S, Virna S, Patrascan CC, Zimmermann S, Herz U, et al. Perinatal maternal application of Lactobacillus rhamnosus GG suppresses sodium pentobarbital anesthesia, and all efforts were made to minimize suffering.

\section{AUTHOR CONTRIBUTIONS}

FG, AZ, and GF conceived and designed the project. FG, TL-M, and IA performed the experiments. FG, SB, TL-M, and IA analyzed the data. FG and AZ wrote the manuscript. SS-Z, SB, GF, AZ, and FG reviewed and edited the manuscript. FG, TL-M, and IA performed/assisted with experiments. FG performed the microbiota analysis. GF contributed reagents/materials/analysis tools. GF and SS-Z obtained the funding and ST helped out with technical assistance and helpful discussions.

\section{FUNDING}

This research was funded by Division of Pharmacology, Utrecht Institute for Pharmaceutical Sciences (UIPS), Faculty of Science, Utrecht University, The Netherlands and department of food science and technology, Isfahan University of Technology.

\section{ACKNOWLEDGMENTS}

The authors thank Suzan Thijssen and Mara A. P. Diks the skillful lab technicians for the technical support in the sorting of flow cytometry samples, also Minoo Badieeyan for technical comments.

\section{SUPPLEMENTARY MATERIAL}

The Supplementary Material for this article can be found online at: https://www.frontiersin.org/articles/10.3389/fimmu. 2020.01092/full\#supplementary-material allergic airway inflammation in mouse offspring. Clin Exp Allergy. (2007) 37:348-57. doi: 10.1111/j.1365-2222.2007.02671.x

7. Theiler A, Bärnthaler T, Platzer W, Richtig G, Peinhaupt M, Rittchen $\mathrm{S}$, et al. Butyrate ameliorates allergic airway inflammation by limiting eosinophil trafficking and survival. J Allergy Clin Immunol. (2019) 144:76476. doi: 10.1016/j.jaci.2019.05.002

8. Górska S, Schwarzer M, Srutkova D, Hermanova P, Brzozowska E, Kozakova H, et al. Polysaccharides L900/2 and L900/3 isolated from Lactobacillus rhamnosus LOCK 0900 modulate allergic sensitization to ovalbumin in a mouse model. Microb Biotechnol. (2017) 10:586-93. doi: 10.1111/1751-7915.12606

9. Kim N, Kunisawa J, Kweon M, Eog Ji G, Kiyono H. Oral feeding of Bifidobacterium bifidum (BGN4) prevents $\mathrm{CD}^{+}{ }^{+} \mathrm{CD} 45 \mathrm{RBhigh} \mathrm{T}$ cellmediated inflammatory bowel disease by inhibition of disordered $\mathrm{T}$ cell activation. Clin Immunol. (2007) 123:30-9. doi: 10.1016/j.clim.2006. 11.005

10. Pellaton C, Nutten S, Thierry A, Boudousquié C, Barbier N, Blanchard C, et al. Intragastric and intranasal administration of Lactobacillus paracasei NCC2461 modulates allergic airway inflammation in mice. Int J Inflam. (2012) 2012:1-8. doi: 10.1155/2012/686739

11. Matsuzaki T, Chin J. Modulating immune responses with probiotic bacteria. Immunol Cell Biol. (2000) 78:67-73. doi: 10.1046/j.1440-1711.2000.00887.x

12. Ruszczynski M, Feleszko W. Probiotics and prebiotics for the prevention or treatment of allergic asthma. In: Watson RR, Preedy VR, editors. Probiotics, Prebiotics, and Synbiotics. London: Elsevier (2016). p. 849-64. 
13. West CE, Jenmalm MC, Kozyrskyj AL, Prescott SL. Probiotics for treatment and primary prevention of allergic diseases and asthma: looking back and moving forward. Expert Rev Clin Immunol. (2016) 12:62539. doi: 10.1586/1744666X.2016.1147955

14. Mangell P, Nejdfors P, Wang M, Ahrné S, Weström B, Thorlacius H, et al. Lactobacillus plantarum 299v inhibits Escherichia coli-induced intestinal permeability. Dig Dis Sci. (2002) 47:511-6. doi: 10.1023/a:1017947531536

15. Earl CS, An S, Ryan RP. The changing face of asthma and its relation with microbes. Trends Microbiol. (2015) 23:408-18. doi: 10.1016/j.tim.2015.03.005

16. Gourbeyre P, Denery S, Bodinier M. Probiotics, prebiotics, and synbiotics: impact on the gut immune system and allergic reactions. J Leukoc Biol. (2011) 89:685-95. doi: 10.1189/jlb.1109753

17. Karaman M, Firinci F, Cilaker S, Uysal P, Tugyan K, Yilmaz O, et al. Antiinflammatory effects of curcumin in a murine model of chronic asthma. Allergol Immunopathol. (2012) 40:210-14. doi: 10.1016/j.aller.2011.04.006

18. Yao J, Jiang M, Zhang Y, Liu X, Du Q, Feng G. Chrysin alleviates allergic inflammation and airway remodeling in a murine model of chronic asthma. Int Immunopharmacol. (2016) 32:24-31. doi: 10.1016/j.intimp.2016.01.005

19. Ghiamati Yazdi F, Soleimanian-Zad S, van den Worm E, Folkerts G. Turmeric extract: potential use as a prebiotic and anti-inflammatory compound? Plant Foods Hum Nutr. (2019) 74:293-9. doi: 10.1007/s11130-019-00733-x

20. Singh G, Kapoor IPS, Singh P, de Heluani CS, de Lampasona MP, Catalan CAN. Comparative study of chemical composition and antioxidant activity of fresh and dry rhizomes of turmeric (curcuma longa linn.). Food Chem Toxicol. (2010) 48:1026-31. doi: 10.1016/j.fct.2010.01.015

21. Akbari-Alavijeh S, Soleimanian-Zad S, Sheikh-Zeinoddin M, Hashmi S. Pistachio hull water-soluble polysaccharides as a novel prebiotic agent. Int J Biol Macromol. (2018) 107:808-16. doi: 10.1016/j.ijbiomac.2017.09.049

22. Abbring S, Verheijden KAT, Diks MAP, Leusink-Muis A, Hols G, Baars T, et al. Raw cow's milk prevents the development of airway inflammation in a murine house dust mite-induced asthma model. Front Immunol. (2017) 8:1045. doi: 10.3389/fimmu.2017.01045

23. Özdemir Ö. Various effects of different probiotic strains in allergic disorders: an update from laboratory and clinical data. Clin Exp Immunol. (2010) 160:295-304. doi: 10.1111/j.1365-2249.2010.04109.x

24. Vos AP, van Esch BC, Stahl B, M'Rabet L, Folkerts G, Nijkamp FP, et al. Dietary supplementation with specific oligosaccharide mixtures decreases parameters of allergic asthma in mice. Int Immunopharmacol. (2007) 7:15827. doi: 10.1016/j.intimp.2007.07.024

25. Sagar S, Vos AP, Morgan ME, Garssen J, Georgiou NA, Boon L, et al. The combination of Bifidobacterium breve with non-digestible oligosaccharides suppresses airway inflammation in a murine model for chronic asthma. Biochim Biophys Acta Mol Basis Dis. (2014) 1842:57383. doi: 10.1016/j.bbadis.2014.01.005

26. van der Aa LB, van Aalderen WMC, Heymans HSA, Henk Sillevis Smitt J, Nauta AJ, Knippels LMJ, et al. Synbiotics prevent asthmalike symptoms in infants with atopic dermatitis. Allergy. (2011) 66:1707. doi: 10.1111/j.1398-9995.2010.02416.x

27. Jang S, Kim H-J, Kim Y-J, Kang M, Kwon J, Seo J, et al. Asthma prevention by Lactobacillus Rhamnosus in a mouse model is associated with $\mathrm{CD}^{+} \mathrm{CD}^{+} 5^{+}$Foxp3 $^{+} \mathrm{T}$ cells. Allergy Asthma Immunol Res. (2012) 4:150. doi: 10.4168/aair.2012.4.3.150

28. Feleszko W, Jaworska J, Rha R, Steinhausen S, Avagyan A, Jaudszus A, et al. Probiotic-induced suppression of allergic sensitization and airway inflammation is associated with an increase of $\mathrm{T}$ regulatory-dependent mechanisms in a murine model of asthma. Clin Exp Allergy. (2007) 37:498505. doi: 10.1111/j.1365-2222.2006.02629.x

29. Jung W, Lee D-Y, Choi YH, Yea SS, Choi I, Park S, et al. Caffeic acid phenethyl ester attenuates allergic airway inflammation and hyperresponsiveness in murine model of ovalbumin-induced asthma. Life Sci. (2008) 82:797805. doi: 10.1016/j.lfs.2008.01.014

30. Das M, Ram A, Ghosh B. Luteolin alleviates bronchoconstriction and airway hyperreactivity in ovalbumin sensitized mice. Inflamm Res. (2003) 52:101-6. doi: 10.1007/s000110300021

31. Carroll N, Cooke C, James A. The distribution of eosinophils and lymphocytes in the large and small airways of asthmatics. Eur Respir J. (1997) 10:292300. doi: 10.1183/09031936.97.10020292
32. Halwani R, Vazquez-Tello A, Sumi Y, Pureza MA, Bahammam A, Al-Jahdali $\mathrm{H}$, et al. Eosinophils induce airway smooth muscle cell proliferation. J Clin Immunol. (2013) 33:595-604. doi: 10.1007/s10875-012-9836-3

33. Koelink PJ, Overbeek SA, Braber S, Morgan ME, Henricks PAJ, Roda MA, et al. Collagen degradation and neutrophilic infiltration: a vicious circle in inflammatory bowel disease. Gut. (2014) 63:578-87. doi: 10.1136/gutjnl-2012-303252

34. Gregory LG, Lloyd CM. Orchestrating house dust mite-associated allergy in the lung. Trends Immunol. (2011) 32:402-11. doi: 10.1016/j.it.2011.06.006

35. Oboki K, Nakae S, Matsumoto K, Saito H. IL-33 and airway inflammation. Allergy Asthma Immunol Res. (2011) 3:81. doi: 10.4168/aair.2011.3.2.81

36. Zakeri A, Russo $M$. Dual role of toll-like receptors in human and experimental asthma models. Front Immunol. (2018) 9:1027. doi: 10.3389/fimmu.2018.01027

37. Zakeri A, Yazdi FG. Toll-like receptor-mediated involvement of innate immune cells in asthma disease. Biochim Biophys Acta Gen Subj. (2017) 1861:3270-7. doi: 10.1016/j.bbagen.2016.08.009

38. Bosnjak B, Stelzmueller B, Erb KJ, Epstein MM. Treatment of allergic asthma: modulation of Th2 cells and their responses. Respir Res. (2011) 12:114. doi: 10.1186/1465-9921-12-114

39. Vercelli D, Jabara HH, Lee BW, Woodland N, Geha RS, Leung DY. Human recombinant interleukin 4 induces Fc epsilon R2/CD23 on normal human monocytes. J Exp Med. (1988) 167:1406-16. doi: 10.1084/jem.167.4.1406

40. Burgess JK, Lee JH, Ge Q, Ramsay EE, Poniris MH, Parmentier J, et al. Dual ERK and phosphatidylinositol 3-kinase pathways control airway smooth muscle proliferation: differences in asthma. J Cell Physiol. (2008) 216:6739. doi: $10.1002 /$ jcp. 21450

41. Pilette C, Francis JN, Till SJ, Durham SR. CCR4 ligands are up-regulated in the airways of atopic asthmatics after segmental allergen challenge. Eur Respir J. (2004) 23:876-84. doi: 10.1183/09031936.04.00102504

42. Vroman H, van den Blink B, Kool M. Mode of dendritic cell activation: the decisive hand in Th2/Th17 cell differentiation. Implications in asthma severity? Immunobiology. (2015) 220:25461. doi: 10.1016/j.imbio.2014.09.016

43. Borish L, Steinke JW. Interleukin-33 in asthma: how big of a role does it play? Curr Allergy Asthma Rep. (2011) 11:7-11. doi: 10.1007/s11882-010-0153-8

44. Makrinioti H, Toussaint M, Jackson DJ, Walton RP, Johnston SL. Role of interleukin 33 in respiratory allergy and asthma. Lancet Respir Med. (2014) 2:226-37. doi: 10.1016/S2213-2600(13)70261-3

45. Gholizadeh P, Mahallei M, Pormohammad A, Varshochi M, Ganbarov K, Zeinalzadeh E, et al. Microbial balance in the intestinal microbiota and its association with diabetes, obesity and allergic disease. Microb Pathog. (2019) 127:48-55. doi: 10.1016/j.micpath.2018.11.031

46. Dang AT, Marsland BJ. Microbes, metabolites, and the gut-lung axis. Mucosal Immunol. (2019) 12:843-50. doi: 10.1038/s41385-019-0160-6

47. Chung KF. Airway microbial dysbiosis in asthmatic patients: a target for prevention and treatment? J Allergy Clin Immunol. (2017) 139:107181. doi: 10.1016/j.jaci.2017.02.004

48. Zhang J, Ma J, Li Q, Su H, Sun X. Lactobacillus rhamnosus GG induced protective effect on allergic airway inflammation is associated with gut microbiota. Cell Immunol. (2018) 332:7784. doi: 10.1016/j.cellimm.2018.08.002

49. Cait A, Hughes MR, Antignano F, Cait J, Dimitriu PA, Maas KR, et al. Microbiome-driven allergic lung inflammation is ameliorated by short-chain fatty acids. Mucosal Immunol. (2018) 11:785-95. doi: 10.1038/mi.2017.75

50. Luu M, Visekruna A. Short-chain fatty acids: bacterial messengers modulating the immunometabolism of $\mathrm{T}$ cells. Eur J Immunol. (2019) 49:8428. doi: 10.1002/eji.201848009

51. Feng W, Ao H, Peng C. Gut microbiota, short-chain fatty acids, and herbal medicines. Front Pharmacol. (2018) 9:1-12. doi: 10.3389/fphar.2018.01354

52. Shinde T, Perera AP, Vemuri R, Gondalia SV, Beale DJ, Karpe $\mathrm{AV}$, et al. Synbiotic supplementation with prebiotic green banana resistant starch and probiotic Bacillus coagulans spores ameliorates gut inflammation in mouse model of inflammatory bowel diseases. Eur J Nutr. (2020) doi: 10.1007/s00394-020-02200-9

53. Lin H-H, Stacey M. G Protein-Coupled Receptors in Macrophages. Microbiol Spectr. (2016) 4:57. doi: 10.1128/microbiolspec.MCHD-0028-2016 
54. Trompette A, Gollwitzer ES, Yadava K, Sichelstiel AK, Sprenger N, NgomBru C, et al. Gut microbiota metabolism of dietary fiber influences allergic airway disease and hematopoiesis. Nat Med. (2014) 20:159166. doi: $10.1038 / \mathrm{nm} .3444$

55. Zhao Y, Yang J, Gao Y, Guo W. Th17 Immunity in Patients with Allergic Asthma. Int Arch Allergy Immunol. (2010) 151:297307. doi: $10.1159 / 000250438$

56. Nonaka M, Bao X, Matsumura F, Gotze S, Kandasamy J, Kononov A, et al. Synthetic di-sulfated iduronic acid attenuates asthmatic response by blocking T-cell recruitment to inflammatory sites. Proc Natl Acad Sci. (2014) 111:8173-8178. doi: 10.1073/pnas.13198 70111

57. Verheijden KAT, Braber S, Leusink-Muis T, Jeurink P V, Thijssen S, Kraneveld $\mathrm{AD}$, et al. The Combination Therapy of Dietary Galacto-Oligosaccharides With Budesonide Reduces Pulmonary Th2 Driving Mediators and Mast Cell Degranulation in a Murine Model of House Dust Mite Induced Asthma. Front Immunol. (2018) 9:1-12. doi: 10.3389/fimmu.2018. 02419
58. Saluja R, Ketelaar ME, Hawro T, Church MK, Maurer M, Nawijn MC. The role of the IL-33/IL-1RL1 axis in mast cell and basophil activation in allergic disorders. Mol Immunol. (2015) 63:80-5. doi: 10.1016/j.molimm.2014.06.018

59. Annunziato F, Romagnani C, Romagnani S. The 3 major types of innate and adaptive cell-mediated effector immunity. J Allergy Clin Immunol. (2015) 135:626-35. doi: 10.1016/j.jaci.2014.11.001

Conflict of Interest: The authors declare that the research was conducted in the absence of any commercial or financial relationships that could be construed as a potential conflict of interest.

Copyright (ㄷ 2020 Ghiamati Yazdi, Zakeri, Ark, Leusink-Muis, Braber, SoleimanianZad and Folkerts. This is an open-access article distributed under the terms of the Creative Commons Attribution License (CC BY). The use, distribution or reproduction in other forums is permitted, provided the original author(s) and the copyright owner(s) are credited and that the original publication in this journal is cited, in accordance with accepted academic practice. No use, distribution or reproduction is permitted which does not comply with these terms. 